
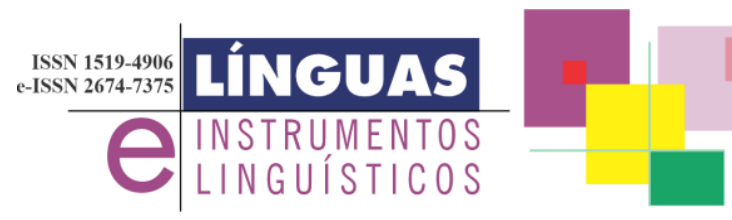

DOI: $10.20396 /$ lil.v24i47.8661757

\title{
Questões da Aquisição de Linguagem no Diretório de Grupos de Pesquisa do CNPq
}

\section{Language Acquisition issues in the CNPq Research Groups Directory}

\section{Luiz Carlos Souza Bezerra* \\ UFPA}

Resumo: Este trabalho discute questões do campo de aquisição de linguagem, como subárea da Linguística, com base no Diretório de Grupos de Pesquisa do CNPq. Os resultados sugerem o desenvolvimento crescente da aquisição de linguagem como campo de investigação, com a emergência de grupos de pesquisa, o aumento do número de pesquisadores e a configuração de linhas de pesquisa em programas de pós-graduação stricto sensu. Os 29 grupos de pesquisa que compõem a amostra concentram-se em três regiões geográficas brasileiras: Sudeste, Sul e Nordeste. A pesquisa evidencia ainda que as atividades de pesquisa contribuem para a configuração da aquisição de linguagem como campo de conhecimento autônomo, híbrido, plural e móvel.

Palavras-chave: Aquisição de linguagem, Linguística, Campo de conhecimento, Grupos de pesquisa.

Abstract: This work discusses some issues in the field of language acquisition, as a subarea of Linguistics, based on the CNPq Research Groups Directory. The results suggest the increasing development of language acquisition as a field of research, with the rise of research groups, the increase in the number of researchers and the configuration 
of lines of research in stricto sensu graduate programs. The 29 research groups that make up the sample are concentrated in three Brazilian geographic regions: Southeast, South and Northeast. The research also demonstrates that the research activities contribute to the configuration of language acquisition as an autonomous, hybrid, plural and mobile field of knowledge.

Keywords: Language acquisition, Linguistics, Field of knowledge, Research groups.

\section{Sobre a aquisição de linguagem, a pesquisa e o pesquisador}

Este trabalho discute questões do campo da aquisição de linguagem ${ }^{1}$, com base no Diretório de Grupos de Pesquisa (DGP) do Conselho Nacional de Desenvolvimento Científico e Tecnológico (CNPq). Entende-se a aquisição de linguagem - apesar de ser estudada por diferentes campos do conhecimento - como subárea da Linguística, não apenas porque não prescinde de uma concepção de linguagem, mas também porque os estudos aquisicionais possibilitam o exercício da reflexão teórica. Destaca-se, assim, que o estudo da aquisição de linguagem é um fenômeno inerente aos estudos linguísticos.

Conforme Auroux (2014, p. 13), a Linguística "[...] é uma forma de saber e de prática teórica nascida no século XIX em um contexto determinado, que possui objetos determinados". Para o autor, as questões que subjaziam à forma de saber e à prática teórica que marcam o surgimento da Linguística como ciência são "o parentesco das línguas, a explicação histórica, as línguas nelas e por elas mesmas" (AUROUX, 2014, p. 13). Segundo esse autor, "trata-se pois de uma forma de estruturação do saber eminentemente transitória" (AUROUX, 2014, p. 13), visto que o conhecimento sobre a linguagem se constitui no tempo, em contextos político-histórico-acadêmicos específicos. Assim, para analisar a produção do conhecimento, remete-se à constituição histórica e ao contexto político-acadêmico em que os pesquisadores estão imersos. O saber instituído e o instituinte são marcados por relações, porque não se define o contemporâneo sem o retorno ao passado (AGAMBEN, 2009). Nesse caso, seguindo essa linha de reflexão, é possível pensar a Linguística, mais especificamente 
a Aquisição de Linguagem, como um dispositivo que se insere numa dimensão histórico-política.

Para Agamben (2009), "dispositivo" é um termo técnico e estratégico no pensamento de Foucault. Conforme esse filósofo, o termo passa a ser frequente no pensamento foucaultiniano a partir dos anos sessenta, apesar de não ter sido definido. Ele aparece numa entrevista concedida por Foucault (1977 apud AGAMBEN, 2009, p. 28) como conjunto

[...] heterogêneo que implica discursos, instituições, estruturas arquitetônicas, decisões regulamentares, leis, medidas administrativas, enunciados científicos, proposições morais e filantrópicas.

Para Foucault, dispositivo, em resumo, pode ser "tanto o dito como o não dito", ou seja, "é a rede que se estabelece entre estes elementos"; ainda segundo o autor, "o dispositivo tem [...] uma função estratégica" e insere-se num "jogo de poder", estando ligado "aos limites do saber, que derivam [...] e o condicionam" (1977 apud AGAMBEN, 2009, p. 28).

Agamben (2009), a partir de Foucault, propõe uma "genealogia" do termo "dispositivo". Assim, "dispositivo" aproxima-se do termo grego oikonomia - que desempenhou importante função na teologia. Em grego, oikonomia designa "administração do oikos, da casa, e, mais geralmente, gestão, management" (AGAMBEN, 2009, p. 35). Para Agamben (2009), com base em Aristóteles, oikonomia não é um paradigma epistêmico, "mas [...] uma práxis, [...] uma atividade prática que deve de quando em quando fazer frente a um problema e a uma situação particular" (AGAMBEN, 2009, p. 35). Em outro momento, o filósofo afirma que a oikonomia refere-se "a um conjunto de práxis, de saberes, de medidas, de instituições cujo objetivo é gerir, governar, controlar e orientar, num sentido que se supõe útil, os gestos e os pensamentos dos homens" (AGAMBEN, 2009, p. 39).

Seguindo a discussão sobre dispositivo, em outro momento, Agamben (2009, p. 40) apresenta uma tentativa de "individuar", ou seja, de desenvolver o conceito de dispositivo para além do conceito foucaultiniano e do sentido grego da palavra. Propõe uma divisão em 
dois grupos ou classes: a) "os seres viventes (ou as substâncias)" e b) "os dispositivos em que estes são incessantemente capturados". Em seguida, o autor apresenta uma definição de dispositivo:

[...] chamarei de dispositivo qualquer coisa que tenha de algum modo a capacidade de capturar, orientar, determinar, interceptar, modelar, controlar e assegurar os gestos, as condutas, as opiniões e os discursos dos seres viventes. Não somente, portanto, as prisões, os manicômios, o Panóptico, as escolas, a confissão, as fábricas, as disciplinas, as medidas jurídicas etc., cuja conexão com o poder é num certo sentido evidente, mas também a caneta, a escritura, a literatura, a filosofia, a agricultura, o cigarro, a navegação, os computadores, os telefones celulares e - por que não - a própria linguagem, que talvez é o mais antigo dos dispositivos, em que há milhares e milhares de anos um primata provavelmente sem se dar conta das consequências que se seguiriam - teve a inconsciência de se deixar capturar (AGAMBEN, 2009, p. 40-41).

Aquisição de Linguagem como dispositivo significa um conjunto de práticas e de saberes que se instituem numa dimensão político-histórica. Trata-se de um dispositivo que produz discursividades, que, por sua vez, produzem efeitos no pesquisador. Para Agamben, a relação do sujeito com o dispositivo é sobretudo uma relação de assujeitamento. Pode-se pensar, com Agamben, que o sujeito emerge entre os seres viventes e os dispositivos.

Conforme o autor, desde o aparecimento do Homo sapiens, há dispositivos, porém é na contemporaneidade que se dá a proliferação em massa de dispositivos, sendo aceito que "hoje não haveria um só instante na vida dos indivíduos que não seja modelado, contaminado ou controlado por algum dispositivo" (AGAMBEN, 2009, p. 42). Daí o surgimento dos dispositivos no "processo de hominização", ou seja, é próprio do humano criar dispositivos. Mas, nesse caso, não cabe ao sujeito destruí-los, importa usá-los de modo correto, afirma Agamben (2009, p. 42). Pode-se pensar, como Agamben, numa relação 
constitutiva marcada pelo assujeitamento e pela criação, uma vez que, para o autor, "o dispositivo é, antes de tudo, uma máquina que produz subjetivações e somente enquanto tal é também uma máquina de governo" (AGAMBEN, 2009, p. 46). A partir daí, Agamben desenvolve o conceito de "profanação": "A profanação é o contradispositivo que restitui ao uso comum aquilo que o sacrifício tinha separado e dividido" (AGAMBEN, 2009, p. 45).

Conceber o conceito de dispositivo na relação com as disciplinas científicas, a partir de Agamben, é conceber o pesquisador imerso em formações discursivas que tanto o constituem como pesquisador, quanto produzem assujeitamento. Nesse contexto, estão inseridos a aquisição de linguagem - como disciplina científica ou dispositivo - e o pesquisador. Assim, pode-se compreender o pesquisador assujeitado aos dispositivos que a ciência impõe. A linguística - como estudo científico da linguagem e como qualquer disciplina científica configura-se como dispositivo e subdivide-se em ramos, áreas, subáreas (ROBINS, 1981); uma dessas subáreas é a aquisição de linguagem objeto de discussão neste trabalho.

A Aquisição de Linguagem, como subárea da Linguística, possui uma longa trajetória de estudos. Porém, os estudos aquisicionais tomam relevo a partir da década de 60 do século XX (ELLIOT, 1982). No Brasil, essa área foi institucionalizada, como campo de estudo e de pesquisa, a partir da fundação de um projeto de pesquisa em aquisição de linguagem no Instituto de Estudos da Linguagem (IEL) da Universidade Estadual de Campinas (Unicamp), em 1976, pela pesquisadora Cláudia Thereza Guimarães de Lemos. Essa pesquisadora coordenou esse projeto entre os anos de 1976 e 1995 (LEMOS, 2001, 2002, 2014).

A Aquisição de Linguagem - uma das áreas mais promissoras dos estudos da linguagem - apresenta-se com crescimento crescente, conforme destacam Elliot (1982) e Fletcher e MacWhinney (1995). Destaca-se que essa área surge, nos estudos da linguagem, em torno da questão do modo como ocorre a passagem do infans a sujeito falante (CASTRO; FIGUEIRA, 2006). Dito de outra maneira, remetendo ao problema de Platão, o problema lógico da aquisição de linguagem reside em descobrir "como a criança consegue saber tanto com tão pouca evidência, ou com dados tão imperfeitos” (KATO, 1999, p. 19). 
Esse problema, no campo em discussão, põe em xeque questões sobre a natureza da linguagem e do desenvolvimento, conforme Elliot (1982, p. 10) pontua: "voltamos sempre aos debates sobre a autonomia da linguagem e a continuidade do desenvolvimento". Essa autora lança algumas questões para o campo: a) "até que ponto é possível abordar a linguagem sem considerar outros sistemas simbólicos ou de comunicação ou de outras fontes de conhecimento?"; b) "até que ponto o desenvolvimento deve ser encarado como uma mudança gradual e quantitativa num corpo de conhecimentos ou de aptidões e até que ponto deve ser encarado como uma série de mudanças qualitativas?" (ELLIOT, 1982, p. 10).

Em outra perspectiva, Lemos (2006) põe em suspenso a noção de desenvolvimento e as tentativas de descrição da fala da criança no campo da aquisição de linguagem. Conforme a autora, "o desenvolvimento linguístico tem sido definido como processo de aprendizagem, ou de construção de conhecimento, necessário para que a criança venha a ser falante nativo de uma língua" (LEMOS, 2006, p. 21, grifo da autora). Acrescenta a autora: "há razões para sustentar que a linguagem não se ajusta a esse quadro", visto que a concepção de linguagem que geralmente caracteriza o campo parte da premissa da linguagem "como objeto que pode ser parcelado ou cujas propriedades podem ser acessadas por uma série ordenada de processos reorganizacionais" (LEMOS, 2006, p. 21, grifo da autora) e uma concepção de criança como sujeito epistêmico (LEMOS, 1992, 2006).

No que concerne às "tentativas de descrição da fala da criança", em aquisição de linguagem, Lemos (2006, p. 22) argumenta que essas tentativas, "[...] guiadas pelo objetivo de estabelecer estágios de desenvolvimento ou de conhecimento, em sua grande maioria, enfrentaram a impossibilidade de transformar teorias linguísticas em instrumentais descritivos". Portanto, no campo da aquisição de linguagem, a emergência da linguagem, a ontogênese da linguagem e a noção de desenvolvimento são pontos nodais de discussão, problemas e impasses. Assim como Lemos (1982, 2002, 2006), Maia (1985, p. 102) advoga que o impasse na pesquisa em aquisição de linguagem deveu-se, em parte, ao fato de alguns "modelos linguísticos ter um caráter processual", porém, os "processos linguísticos stricto sensu são em geral conceptualizados espacialmente". Em outros termos, conforme a autora, "os modelos linguísticos falam em níveis, strata, 
componentes; os modelos psicolingüísticos, desavisadamente, traduzem-nos em termos de períodos, estágios, fases" (MAIA, 1985, p. 102). Esse impasse contribuiu para pensar em uma dimensão temporal ou estrutural nos estudos da aquisição de linguagem (LEMOS, 1982, 1992; 2006; LIER-DEVITTO, 1983; MAIA, 1985).

A aquisição de linguagem intriga pesquisadores e é um terreno profícuo para questionamentos sobre os estudos da linguagem. Logo, estudar como a criança adquire a linguagem é uma questão para pesquisadores e para as teorias linguísticas, bem como para a filosofia, as ciências cognitivas, as psicologias (desenvolvimento, aprendizagem, cognitiva), neurociências, inteligência artificial, entre outras áreas (CASTRO; FIGUEIRA, 2006; FLETCHER; MACWHINNEY, 1995; SCARPA, 2012). Destaca-se, portanto, o caráter móvel da aquisição de linguagem, que, por sua vez, marca diferentes campos do conhecimento.

O campo da aquisição de linguagem - que se constitui em torno da linguagem da criança - configura-se como um dispositivo, uma vez que funciona como um conjunto de práxis, de saberes, de produção de conhecimento (AGAMBEN, 2009), que, por seu turno, insere o campo num "microcosmo dotado de suas leis próprias" (BOURDIEU, 2004, p. 20). Esse campo de conhecimento ou dispositivo é constituído de "agentes e instituições que produzem, reproduzem ou difundem" conhecimentos e saberes. Esse campo, considerado um universo, "é um mundo social como os outros, mas que obedece a leis sociais mais ou menos específicas" (BOURDIEU, 2004, p. 20). Como em qualquer área de conhecimento, o saber consiste numa dimensão histórico-política em que os pesquisadores estão inseridos ou constituídos. Em outros termos, em diferentes momentos da história, o pesquisador está assujeitado aos dispositivos, como se pode observar, por exemplo, a partir da discussão de Lemos e Campos (1976) sobre as limitações da aplicação do modelo piagetiano $^{2}$ a estudos de aquisição de linguagem. Para as autoras, a década de 70 do século $\mathrm{XX}$ foi caracterizada como adesão ao cognitivismo $^{3}$ nos estudos da aquisição de linguagem. A adesão de pesquisadores da época ao cognitivismo pode ser explicada, com base nas autoras, por três questões: a) a constatação de que "as gramáticas pivô, além de não refletirem o conhecimento linguístico das crianças pela vacuidade das regras propostas, careciam de fundamentação empírica"; b) a dificuldade enfrentada por pesquisadores para "fornecer 
evidência à hipótese de que as estruturas linguísticas são inatas, ou a sua versão menos extrema, de que o ser humano é dotado de um mecanismo específico para adquirir linguagem"; c) o reconhecimento "de que na primeira fase sintática, ou de dois vocábulos, as regularidades que se detectam na fala das crianças são de natureza predominantemente semântica" (LEMOS; CAMPOS, 1976, p. 51-52). Nesse caso, os pesquisadores, sob a influência de perspectivas teóricas dominantes na época, estavam em busca de respostas para explicar a linguagem da criança. Assim, destaca-se o pesquisador assujeitado ao dispositivo e inserido numa dimensão histórico-política do campo de estudo.

A relação criança-linguagem é uma questão fundadora que instiga pesquisadores a sustentar diversas possibilidades de teorização, seja recorrendo à linguística, seja remetendo a diferentes campos de conhecimento. De início, percebe-se que lidar com a relação linguagem-criança, apesar de instigante, não é uma tarefa simples, assim como não há uma única forma de questionar essa relação. Nesse caso, se há mais de uma forma de questionar a relação criançalinguagem é porque o campo assenta-se numa pluralidade teóricometodológica e, por conseguinte, anuncia a aquisição de linguagem como uma área caracterizada pela pluralidade teórica e pelo caráter interdisciplinar. Em suma, a aquisição de linguagem é considerada uma área híbrida, heterogênea ou multidisciplinar (CORRÊA, 2006; SCARPA, 2012).

A interdisciplinaridade ${ }^{4}$ é convocada em razão da natureza e da complexidade da relação criança-linguagem. O direcionamento a campos disciplinares diversos dá-se pela própria limitação da Linguística para resolver de per si o problema anunciado. Assim, destaca-se o teorema formulado por Jacques Labeyrie (apud MORIN, 2012, p. 107): "quando não se encontra solução em uma disciplina, a solução vem de fora da disciplina". Esse teorema serve para ilustrar os movimentos de pesquisadores da aquisição de linguagem na elaboração de programas de pesquisa: por um lado, filiam-se à(s) teoria(s) da linguagem e, por outro, vinculam-se a diversos campos disciplinares.

O teorema de Jacques Labeyrie não enfatiza o caráter utilitarista de campos de conhecimentos distintos; sugere a inter-relação entre as disciplinas, o que, por sua vez, implica um problema, visto que nenhuma disciplina é redutível a outra (MORIN, 2012, p. 113). Assim 
sendo, enfrenta-se o problema de encontrar a inter-relação, visto que cada disciplina tem "não apenas sua linguagem própria, mas também conceitos fundamentais que não podem ser transferidos de uma linguagem à outra" (MORIN, 2012, p. 113-114). Entretanto, isso não impede migrações de conceitos entre disciplinas, uma vez que "algumas noções migradoras fecundam um novo terreno, onde vão enraizar-se, ainda que à custa de um contra-senso" (MORIN, 2012, p. 108), como é o caso da aquisição de linguagem. Para Morin (2012, p. 107), a história da ciência é marcada pela constituição, pela proliferação de disciplinas, bem como por "[...] rupturas entre fronteiras disciplinares, [pela] invasão de um problema de uma disciplina por outra, [pela] circulação de conceitos, [pela] formação de disciplinas híbridas que acabam tornando-se autônomas". O autor conclui que, "[...] se a história oficial da ciência é a da disciplinaridade, uma outra história, ligada e inseparável, é a das inter-poli-transdisciplinaridades" (MORIN, 2012, p. 107).

No percurso de desenvolvimento da Linguística, constata-se que a hibridação não está circunscrita apenas à subárea da aquisição de linguagem. De fato, basta observar o conjunto de disciplinas constituídas entre estudos linguísticos e campos disciplinares diferentes, como a sociolinguística, a psicolinguística, a análise de discurso, a neurolinguística, a etnolinguística, a biolinguística, entre outras. Como diz Morin (2012, p. 107), a história da ciência é caracterizada pela disciplinarização, mas também por "inter-politransdisciplinaridades", ou melhor, pela hibridação. A relação da linguística com outras ciências foi assinalada por Jakobson (2015, p. 14), para quem é "[...] a rica experiência científica da linguística que nos impele a levantar as questões do lugar que ela ocupa entre as ciências do homem e da perspectiva de uma cooperação interdisciplinar". Entretanto, essa relação híbrida não se deve, segundo o autor, às "necessidades e propriedades intrínsecas de qualquer área" (JAKOBSON, 2015, p. 14). Acredita-se que a relação da linguística com as outras disciplinas, a partir das subáreas dos estudos da linguagem, tem logrado êxito e assegurado o compromisso com as propriedades intrínsecas das disciplinas, conforme é observado nas diversas subáreas da Linguística constituídas sob o prisma da hibridação. 
Em suma, é nesse contexto híbrido, em torno do problema fundador, que surge, nos estudos da linguagem, o campo da aquisição de linguagem, que, por sua vez, constitui um dispositivo, nas palavras de Agamben (2009). Conceber a aquisição de linguagem como um dispositivo requer concebê-la enquanto área de conhecimento ou de investigação. Castro e Figueira (2006, p. 75) afirmam:

[...] no domínio dos estudos da linguagem é hoje aceito que o campo da aquisição de linguagem constitui uma área legítima da investigação científica. Talvez isso não seja imediatamente evidente para muitos leitores e deste modo é relevante indagar: por que a fala da criança é alçada a objeto de pesquisa? A resposta se justifica na medida em que, como se pode observar, a fala da criança não coincide com a do adulto e muitos até argumentariam que ela é fragmentária e incompleta.

Ora, como quer que se apresente esta fala, não se pode ignorar que é a sua especificidade aquilo que a constitui como objeto próprio de investigação. Estudar como emerge a linguagem no infans torna-se inegavelmente uma questão de extrema importância para o conhecimento do ser humano.

Conforme as autoras, a área da aquisição de linguagem, como subárea da Linguística, é uma "área legítima de investigação científica". Entretanto, apesar de possuir um crescimento regular, conforme havia sido notado por Elliot (1982) e Fletcher e MacWhinney (1995), essa área, por vezes, não é compreendida como campo de pesquisa. A dificuldade em reconhecer a aquisição de linguagem como campo deve-se à sua própria configuração. O campo da aquisição de linguagem tem uma lógica própria e goza de autonomia, caracterizando-se por ser híbrido (constituído de teorias de áreas diferentes), móvel (é uma subárea da linguística, mas também das psicologias, da filosofia, das ciências cognitivas, entre outras) e plural (em razão das diferentes perspectivas dos programas de pesquisas). Além disso, a admissão, pelo senso comum, de que é natural adquirir uma língua e ser falante pode dificultar a compreensão de que há um campo, pesquisadores e 
pesquisas sobre algo tão comum e naturalizado - a fala ou a linguagem da criança.

A aquisição de linguagem é considerada uma "área legítima de investigação científica" por ser um campo que possui uma lógica própria (BOURDIEU, 2004), por elevar a fala da criança a objeto de estudo, por atribuir "estatuto teórico" linguístico-discursivo a essa fala (LEMOS, 1992) e, com isso, desnaturalizá-la, tirá-la do senso comum. Esse campo ${ }^{5}$ desnaturaliza o marco original na história do sujeito - que é a aquisição de linguagem - como instantâneo e universal (as crianças seguem sempre o mesmo percurso) porque mostra que esse marco é singular e impregnado de erros (CARVALHO, 1995; FIGUEIRA, 1996; LEMOS, 1992) - "erros estruturantes" e/ou "erros sintomáticos" (ARANTES, 2004, p. 337). Erros fazem erupção tanto na fala patológica como em falas sem patologias (LIER-DEVITTO, 2001, 2006).

Esse campo sustenta explicações sobre o percurso da criança na linguagem e sinaliza que esse percurso é singular: a relação da criança com a linguagem emerge como um "processo de subjetivação" (LEMOS, 2001), porque "a fala inicial da criança mostra uma certa relação da criança com a linguagem, relação essa que não pode ser deixada de lado", destaca Lemos (2006, p. 23). Daí a importância dos estudos sobre aquisição de linguagem. As pesquisas do campo não apenas remetem à linguagem de per si, mas também dizem algo sobre a criança, ou melhor, sobre a relação da criança com a linguagem (FIGUEIRA, 2004; LEMOS, 2004, 2006), o que, nesse caso, é "uma questão de extrema importância para o conhecimento do ser humano" (CASTRO; FIGUEIRA, 2006, p. 75).

Em tese, todo campo é definido a partir de um objeto de estudo, no caso, a aquisição de linguagem é constituído a partir da fala da criança ou, dito de outro modo, da linguagem da criança. Castro e Figueira (2006, p. 75) afirmam que a fala da criança destoa da fala do adulto e apresenta-se como "fragmentária". Como já citado, para as autoras, "como quer que se apresente esta fala, não se pode ignorar que é a sua especificidade aquilo que a constitui como objeto próprio de investigação" (CASTRO; FIGUEIRA, 2006, p. 75). Seguindo essa direção, Carvalho (2004, p. 27, grifo da autora) destaca a "singularidade que marca a fala da criança, durante a sua trajetória linguística"; para ela, a existência do campo da aquisição de linguagem 
decorre da "tentativa de explicar a mudança de uma condição de infans para a condição de falante". Em outras palavras, a fala da criança caracteriza-se por uma especificidade que desconcerta o pesquisador e as teorias e imprime uma lógica própria ao campo. A especificidade da fala da criança põe em suspenso a primazia da teoria e sua aplicação a um corpus linguístico constituído por falas de criança. Portanto, é a especificidade da fala da criança que constitui o campo de estudo. Em suma, a fala da criança apresenta-se como "heterogênea", "imprevisível" e "indeterminada" (LEMOS, 1982, 1992) e toca "em limites consolidados da língua" (FIGUEIRA, 2015, p. 174), o que reforça o argumento de que as falas de crianças "não são passíveis de ser descritas nem explicadas por teorias linguísticas" (LEMOS, 2014, p. 954).

Para o campo da aquisição de linguagem, dado o seu caráter híbrido, móvel e plural e dada a natureza da linguagem da criança, conforme mencionado anteriormente, não há uma única forma de definir o objeto. Conforme Lemos (1995, p. 17), "não se define sempre de um modo idêntico o objeto de uma disciplina e a própria definição do objeto já evidencia uma posição teórica". A aquisição de linguagem assume uma especificidade ao definir seu objeto em função da pluralidade teóricometodológica. Para Lemos, esse campo de investigação congrega “[...] pesquisas muito diferentes entre si, sendo difícil falar da área de um modo geral" (LEMOS, 1995, p. 17). Diante dessa pluralidade, Lemos (1995, p. 17) questiona: "[...] seria legítimo supor que existe alguma coisa partilhada por todos os projetos nessa área"; certamente, prossegue, "não é o objeto que é compartilhado", visto que o objeto é descrito (ou construído) a partir do recorte teórico. Afirma Perroni (1996, p. 17): "não há pesquisa ateórica" nem "metodologia ateórica", uma vez que "[...] qualquer metodologia é determinada pela teoria eleita pelo investigador, assim como é a natureza da unidade de análise".

Embora reconheça que as diferentes possibilidades de teorização coexistem em uma relação de diferença, Lemos (1995, p. 18) admite que há algo em comum: o "[...] compromisso, maior ou menor, com a fala da criança". Portanto, mesmo que esse compromisso "[...] seja para dizer por quais estruturas fala, por que fala do modo que fala, quando é que fala o quê, o fato geral é que a posição teórica do investigador não o liberta de um submetimento a essa fala" (LEMOS, 1995, p. 18). O pesquisador está submetido ao objeto e assujeitado ao dispositivo. Por 
isso, diz Carvalho (2004, p. 27), o pesquisador "assume, implícita ou explicitamente, um compromisso com a singularidade, com a diferença da fala da criança em relação ao falante de sua língua". Em outros termos, os pesquisadores da aquisição de linguagem estão em volta da linguagem da criança, interrogando, interrogando-se e implicando-se na fala da criança.

Em suma, o pesquisador vê-se submetido à especificidade da fala da criança e à teoria. Essa questão pode, em alguns casos, levar a impasses. Segundo Carvalho (2004, p. 27), "a fala da criança, com o seu estatuto de diferença, é produzida como objeto de estudo, por um efeito provocado sobre um sujeito". O sujeito/pesquisador, sob os efeitos da fala da criança e assujeitado à teoria, produz o objeto de estudo. A implicação do sujeito/pesquisador é inevitável, podendo ser considerada como "uma questão ou como um impasse": " $o$ reconhecimento de um efeito provocado sobre um sujeito (o investigador) constitui a fala da criança como objeto de estudo; mas, a constituí-la suspende o seu caráter de objetividade" (CARVALHO, 2004, p. 27, grifo da autora).

O pesquisador - assujeitado ao dispositivo, nesse caso, a teoria enfrenta o impasse da implicação e igualmente o descompasso entre a objetividade e a subjetividade na pesquisa em aquisição de linguagem. Segundo Lemos (1982, p. 98), o pesquisador, no exercício da investigação sobre aquisição de linguagem, defronta-se com "um dilema de base - seu dilema ou "pecado original"'. Em outros termos, o "dilema de base" refere-se à incompatibilidade entre dois compromissos: a) a diacronia - "a identificação e a explicação das mudanças qualitativas que definiriam o processo de aquisição de linguagem", ou, dito de outro modo, o compromisso do pesquisador "com a gênese de estruturas e categorias" linguísticas; b) a sincronia a descrição, "em termos de categorias e estruturas definidas no interior das teorias linguísticas vigentes, [dos] enunciados representativos de cada momento do período que isola como objeto de estudo" (LEMOS, 1982, p. 98). Para a autora, no exercício da pesquisa, há forte indício de que o pesquisador opte pelo segundo compromisso, ou seja, pela descrição da produção linguística da criança "[...] como instanciações de categorias como Nome e Verbo, Agente e Objeto, traços semânticos, regras sintáticas" (LEMOS, 1982, p. 98). Destaca-se, portanto, que a opção feita pelo pesquisador é influenciada pela sua sujeição ao 
dispositivo ou à teoria. $\mathrm{O}$ pesquisador limita-se à possibilidade e ao limite que a teoria ou o dispositivo impõe. Explica Lemos (1982, p. 99):

Se tem ocultado [...] o dilema cujo reconhecimento levaria a análises alternativas e à elaboração de uma metalinguagem que permitisse dar conta das mudanças qualitativas que caracterizam o processo de aquisição de linguagem em um nível menos abstrato e menos terminal. Parece-me consequente a isso o fato de o conjunto de trabalhos representativos da área não oferecer mais que descrições de períodos ou estágios não relacionáveis entre si, não servindo, portanto, à reconstituição de um processo definível, pelo menos em parte, pela sua continuidade (LEMOS, 1982, p. 99).

A relação entre teoria e objeto, objetividade e subjetividade, pesquisador e criança e pesquisador e teoria é uma questão latente no campo da aquisição de linguagem. Se, por um lado, o sujeito/pesquisador enfrenta a especificidade da fala da criança, por outro lado, ele também enfrenta o assujeitamento à teoria/dispositivo. Esse enfrentamento parece ser, portanto, uma questão inevitável. Carvalho (2004, p. 35) indica uma possível superação desse imbróglio. Para a autora, a investigação sobre a fala da criança passa por três momentos: a) "o momento da implicação do investigador"; b) "o momento de refletir sobre a fala da criança a partir de um modelo"; c) "o momento de refletir sobre a fala da criança a partir da quebra desse modelo". Segundo a autora, esses momentos estão imbricados e são constitutivos da pesquisa, e o pesquisador também é implicado. A quebra de modelos teóricos, conforme sinalizado por Carvalho (2004), e a análise alternativa, enfatizada por Lemos (1982), são influenciadas pela relação entre pesquisador e teoria. Considerando que a teoria funciona como um dispositivo, que, por sua vez, conforme Agamben (2009, p. 46), funciona como "máquina que produz subjetivação" e assujeitamento, pensar em quebra de modelos teóricos ou em análises alternativas pressupõe que o pesquisador está preso ao dispositivo/teoria, em um processo de "profanação", ou seja, em um processo de restituição do aprisionamento da lógica da 
teoria/dispositivo e de reflexão sobre a lógica do "objeto" de estudo. O que importa é a posição que o pesquisador ocupa na relação com a teoria/dispositivo: ele tanto pode fazer análises alternativas, como pode fazer um exercício acrítico de aplicação de fragmentos ou de conceitos da teoria ao corpus linguístico de fala ou escrita de crianças.

A partir das considerações tecidas, passa-se a discutir a aquisição de linguagem com base no Diretório de Grupos de Pesquisa do $\mathrm{CNPq}^{6}$. O $\mathrm{DGP} / \mathrm{CNPq}^{7}$ é um registro de grupos de pesquisa científica e tecnológica desenvolvido por pesquisadores no Brasil.

\section{Sobre a metodologia do estudo}

A pesquisa foi realizada a partir do banco de dados do Diretório de Grupos de Pesquisa do CNPq. Inicialmente foi feita uma busca na plataforma do Diretório de Grupos de Pesquisa. Houve, porém, algumas dificuldades para selecionar uma amostra, porque o termo "aquisição de linguagem" é genérico. Desse modo, para superar essa dificuldade, selecionaram-se termos que remetem à área e aplicaram-se filtros para selecionar uma amostra representativa de pesquisadores e atividades científicas ligados à subárea da Linguística. Assim sendo, a busca no site do Diretório de Grupos de Pesquisa do CNPq empregou os termos aquisição de linguagem, aquisição da linguagem, aquisição, desenvolvimento da linguagem, opção todas as palavras, consulta por grupo. Na opção aplicar a busca aos campos, foram selecionados nome do grupo e nome da linha de pesquisa; selecionou-se a opção certificado e não atualizado. A escolha por certificado e não atualizado justifica-se pelo interesse de selecionar apenas grupos certificados pela instituição de ensino e pesquisa; já a opção não atualizado justifica-se pelo fato de ser possível haver grupos não atualizados pelo líder. Seguindo a descrição do filtro de busca, selecionou-se a grande área Linguística, Letras e Artes e a área Linguística e optou-se ainda pela opção predominante do grupo de pesquisa.

Em relação ao filtro referente à formação acadêmica, selecionou-se a opção doutorado e, em titulação máxima, escolheu-se do pesquisador do grupo. Em relação ao filtro para bolsistas ou docentes cadastrados na pós-graduação, foi selecionada apenas a opção docentes da pósgraduação em programas avaliados com notas 7, 6, 5, 4 e 3. A opção para bolsistas de produtividade de pesquisa do $\mathrm{CNPq}$ não foi 
selecionada porque poderia excluir pesquisadores que não possuam bolsa de produtividade.

Após a coleta de dados no Diretório de Grupos de Pesquisa do $\mathrm{CNPq}$, foi constituída uma amostra preliminar de 50 grupos de pesquisa; após uma pré-análise, com base em critérios de inclusão, chegou-se a um corpus de 29 grupos de pesquisa.

\section{Tabela 1 - Processo de constituição do corpus.}

\begin{tabular}{|c|c|}
\hline Amostra & 50 grupos de pesquisa. \\
\hline $\begin{array}{l}\text { Critérios de } \\
\text { inclusão }\end{array}$ & $\begin{array}{l}\text { - grupo de pesquisa cadastrado na área de Letras e } \\
\text { Linguística; } \\
\text { grupo de pesquisa nomeado e/ou com pelo menos } \\
\text { umas das linhas de pesquisa identificadas e/ou com } \\
\text { palavras-chave em referência à aquisição de } \\
\text { linguagem; } \\
\text { - líder do grupo pertencente a Programas de Pós- } \\
\text { Graduação stricto sensu na área de Linguística. }\end{array}$ \\
\hline Corpus & 29 grupos de pesquisa \\
\hline
\end{tabular}

Fonte: Elaboração do autor.

Mesmo com a aplicação de filtros de busca na plataforma do DGP/CNPq e da adoção de critérios de inclusão, permaneceram as dificuldades em constituir uma amostra que evidencie grupos de pesquisa e pesquisadores da subárea da Linguística, visto que o termo "aquisição de linguagem" tem caráter ambíguo e genérico. Nesse caso, foram excluídos os grupos que se enquadravam nos critérios de inclusão, mas nos quais a proposta do grupo e o currículo do líder destoavam do campo da aquisição de linguagem.

O Diretório de Grupos de Pesquisa e o Currículo Lattes do CNPq são plataformas abertas, com possibilidades de atualização pelos pesquisadores. Isso significa que as informações disponíveis podem ser alteradas constantemente. Por isso, foi salva uma cópia do grupo de pesquisa e do currículo Lattes do líder do grupo. A pesquisa nas plataformas Diretório de Grupos de Pesquisa e Currículo Lattes do CNPq ocorreu em 30 de maio de 2020. Após a constituição do corpus, foi realizada pesquisa no currículo Lattes do líder para identificar o programa de pós-graduação e a instituição de ensino superior (IES) aos quais o grupo de pesquisa está vinculado. 


\section{Sobre grupos de pesquisa em aquisição de linguagem: alguns resultados}

A partir do corpus constituído por meio da pesquisa realizada no Diretório de Grupos de Pesquisa, organizaram-se os resultados em dois grupos para análise e discussão: a) Sobre os grupos de pesquisas e programas de pós-graduação e b) Sobre temas frequentes nas linhas de pesquisa.

\subsection{Sobre os grupos de pesquisas e programas de pós-graduação}

A Tabela 2 apresenta a nomeação dos grupos de pesquisa que compõem a amostra, a Instituição de Ensino Superior (IES) à qual se vinculam e o ano de formação dos grupos.

Tabela 2 - Grupos de pesquisa, instituição e ano de fundação.

\begin{tabular}{|l|c|c|}
\hline \multicolumn{1}{|c|}{ Grupo de pesquisa } & IES & Formação \\
\hline $\begin{array}{l}\text { A Expressão da Quantificação nas Línguas } \\
\text { Naturais }\end{array}$ & UFSC & 2001 \\
\hline $\begin{array}{l}\text { Aquisição e Desenvolvimento da Linguagem: } \\
\text { Relações entre Fala e Escrita }\end{array}$ & UNISINOS & 2004 \\
\hline $\begin{array}{l}\text { Aquisição e Sintaxe: Interface Sintaxe- } \\
\text { Semântica }\end{array}$ & UNICAMP & 2007 \\
\hline $\begin{array}{l}\text { Aquisição e Uso de Fonologia em Português } \\
\text { Brasileiro }\end{array}$ & USP & 2004 \\
\hline Aquisição, Patologias e Clínica de Linguagem & PUC-SP & 2002 \\
\hline $\begin{array}{l}\text { Cérebro Infantil: Aquisição de Linguagem e } \\
\text { Outras Cognições }\end{array}$ & UFRJ & 2018 \\
\hline Cognição e Linguística (GELP-COLIN) & UFC & 2000 \\
\hline $\begin{array}{l}\text { Ensino e Aprendizado Típico e Atípico da } \\
\text { Leitura e da Escrita }\end{array}$ & UESBA & 2015 \\
\hline Estudos sobre a Aquisição da Escrita & UEM & 2010 \\
\hline $\begin{array}{l}\text { Fonologia Cognitiva: Investigação de Padrões } \\
\text { Sonoros Emergentes }\end{array}$ & UFMG & 2002 \\
\hline $\begin{array}{l}\text { Grupo de Estudos em Neurolinguística e } \\
\text { Psicolinguística (GENP) }\end{array}$ & PUC-RS & 2010 \\
\hline $\begin{array}{l}\text { Grupo de Estudos em Processamento } \\
\text { Linguístico (GEPROL) }\end{array}$ & UFPB & 2007 \\
\hline
\end{tabular}




\begin{tabular}{|l|c|c|}
\hline $\begin{array}{l}\text { Grupo de Pesquisa e Estudo em } \\
\text { Neurolinguística (GPEN) }\end{array}$ & UESBA & 2007 \\
\hline $\begin{array}{l}\text { Grupo de Pesquisa em Aquisição de } \\
\text { Linguagem (GPAL) }\end{array}$ & UNICAMP & 1996 \\
\hline $\begin{array}{l}\text { Grupo de Pesquisa em Aquisição e } \\
\text { Processamento da Linguagem }\end{array}$ & UFJF & 2006 \\
\hline $\begin{array}{l}\text { Grupo de Pesquisa em Gramática, Aquisição e } \\
\text { Cognição (GRÃO) }\end{array}$ & UFC & 2018 \\
\hline $\begin{array}{l}\text { Laboratório de Bilinguismo e Cognição } \\
\text { (LABICO) }\end{array}$ & UFRGS & 2008 \\
\hline $\begin{array}{l}\text { Laboratório de Compreensão Neurocognitiva } \\
\text { da Linguagem (LACON) }\end{array}$ & UFPB & 2009 \\
\hline $\begin{array}{l}\text { Laboratório de Estudos Enunciativos do Texto } \\
\text { (LEnTe) }\end{array}$ & UFSCar & 2013 \\
\hline $\begin{array}{l}\text { Laboratório de Psicolinguística, Línguas } \\
\text { Minoritárias e Multilinguismo (LAPLIMM) }\end{array}$ & UFPEL & 2019 \\
\hline Linguagem, Distúrbio e Multidisciplinaridade & UNICAP & 2002 \\
\hline Linguagem e Cognição & UNISC & 2003 \\
\hline $\begin{array}{l}\text { Línguas Brasileiras: Análise, Aquisição e } \\
\text { Ensino }\end{array}$ & UFAL & 2008 \\
\hline NALingua & UNESP & 2008 \\
\hline Neurolinguística Discursiva: Afasia e Infância & UNICAMP & 2013 \\
\hline $\begin{array}{l}\text { Núcleo de Estudos Linguísticos Interacionais } \\
\text { (NELIN) }\end{array}$ & UFPB & 2003 \\
\hline $\begin{array}{l}\text { Processamento e Aquisição da Linguagem } \\
\text { (GPPAL) }\end{array}$ & PUC-Rio & 1993 \\
\hline Produtividade Linguística Emergente & UFSC & 1995 \\
\hline Programa de Estudos Linguísticos & UFAL & 1992 \\
\hline
\end{tabular}

Fonte: Elaboração do autor.

A pesquisa evidencia 29 grupos de pesquisa registrados no Diretório de Grupos de Pesquisa do $\mathrm{CNPq}$ vinculados à área de aquisição de linguagem. Uma leitura atenta é suficiente para compreender que a questão da aquisição de linguagem, na linguística, abordada por pesquisadores brasileiros, insere-se em uma área em constante crescimento. Destaca-se que alguns grupos de pesquisa que compõem a amostra não se limitam exclusivamente ao campo da aquisição de linguagem, mas, pela especificidade desse campo, a aquisição de linguagem é referida. 
Ressalta-se a afirmação feita anteriormente de que o campo da aquisição de linguagem configura-se como autônomo, híbrido, móvel e plural. Nota-se, a partir da análise dos grupos, que o caráter híbrido é observado nas diferentes perspectivas teóricas de diferentes campos disciplinares na constituição de programas de pesquisa em aquisição de linguagem. Nota-se ainda que cada grupo de pesquisa possui uma identidade teórica que confere ao campo uma pluralidade teórica e metodológica. Outra característica desse campo é seu caráter móvel: a aquisição de linguagem não fica circunscrita a uma área específica. Ela está presente nas demais subáreas da Linguística e como campo móvel em outras áreas do conhecimento, conforme comentado anteriormente. Esse fato destaca a autonomia do campo da aquisição de linguagem. Esse campo não se restringe nem se condiciona a uma determinada área. Ele é móvel. A aquisição de linguagem é, portanto, um ponto de intersecção e está em permanente diálogo com diversos campos do conhecimento (neurociência, psicanálise, ciências cognitivas, as psicologias, filosofia, entre outras) e com diferentes subáreas da linguística (psicolinguística, neurolinguística, linguagem e cognição). Maia (1985), em uma revisão crítica da literatura psicolinguística, constatou a abordagem de questões concernentes à aquisição de linguagem ou à "gênese" nas pesquisas. Assim, a autora identificou "a insistência com que questões relativas à aquisição da linguagem surgem mesmo quando não constituem o objeto principal de preocupação" (MAIA, 1985, p. 95). A aquisição de linguagem é, portanto, uma questão inerente aos estudos da linguagem

Figura 1 - Período de formação de grupos.

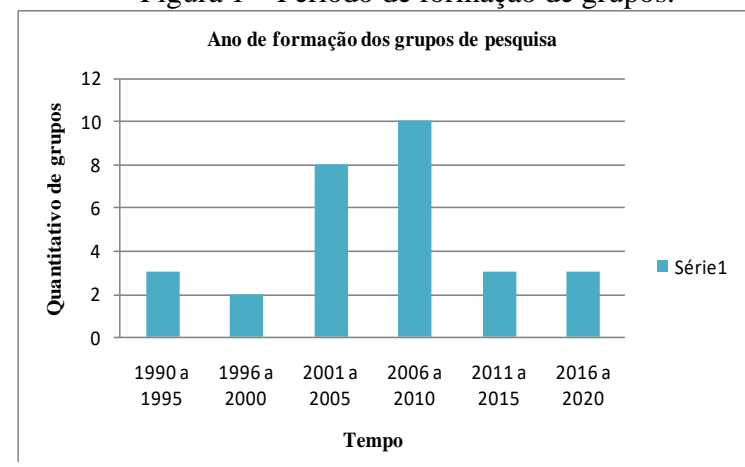

Fonte: Elaboração do autor. 
A Figura 3 mostra a evolução dos grupos de pesquisa na área em estudo. Desde a fundação do primeiro grupo de pesquisa, por Cláudia T. G. de Lemos, em 1976, no IEL (Unicamp), houve um crescimento considerável. Nota-se que inicialmente há um crescimento tímido e, em seguida, um crescimento exponencial; entre 2001 e 2005, esse crescimento acelera-se principalmente entre os anos de 2006 e 2010 . A Figura 3 evidencia ainda um decréscimo e uma estabilização na criação de novos grupos vinculados a programas de pós-graduação no período de 2011 a 2015 e de 2016 a 2020 . O período de crescimento pode ser justificado por três pontos ou, por outras palavras, o crescimento do campo coincide com três fatos: a) a formação de doutores na área; b) a política de expansão da pós-graduação em nível stricto sensu no Brasil; c) a expansão do ensino superior público federal apresentada na política do Reuni (BRASIL, 2007). Observa-se que, nesse período, havia no país um conjunto de fatores propícios ao desenvolvimento da ciência e à formação de pesquisadores.

A Figura 3 sinaliza ainda que, a partir de 2011, começa a haver um decréscimo na criação de novos grupos, o que se reproduz entre os anos de 2016 e 2020. Ressalte-se que esse decréscimo é inferior ao do período de 1996 a 2000. Portanto, o saldo é positivo. Observa-se que a queda no número de novos grupos criados coincide com a própria conjectura político-econômica do país, marcada, entre outros fatos, pelo corte no orçamento das universidades públicas, pela diminuição de vagas de concursos para professor-pesquisador, pela falta de investimentos na pós-graduação, pelo corte de bolsas de pós-graduação (mestrado, doutorado e pós-doutorado) e pelo corte de bolsas de produtividade em pesquisa.

Sabe-se que a evolução de um campo de conhecimento não pode ser explicada apenas pela conjectura político-econômica. Mas é impossível analisá-la sem contextualizá-la, uma vez que, conforme referido anteriormente, o pesquisador está sujeito a condições históricopolíticas. Sobre esse aspecto, Bourdieu (2004, p. 21) afirma: “[...] é preciso escapar à alternativa da 'ciência pura', totalmente livre de qualquer necessidade social, e da 'ciência escrava', sujeita a todas as demandas político-econômicas". Portanto, a conjectura políticoeconômica e histórica pode facilitar ou dificultar a formação de grupos de pesquisa e, consequentemente, o exercício da investigação científica. As políticas de apoio à ciência e à tecnologia podem interferir na 
produção do conhecimento. Assim sendo, destaca-se a importância das agências de fomento à pesquisa para o desenvolvimento da ciência e a produção de conhecimento no país. Contudo, Bourdieu (2004, p. 21) destaca: "o campo científico é um mundo social e, como tal, faz imposições, solicitações etc., que são, no entanto, relativamente independentes das pressões do mundo social global que o envolve". Para o autor, as pressões externas são exercidas por meio do campo científico, "mediatizadas pela lógica do campo" (BOURDIEU, 2004, p. 22). Para Bourdieu, "uma das manifestações mais visíveis da autonomia do campo é a sua capacidade de refratar; retraduzindo sob uma forma específica as pressões ou as demandas externas" (BOURDIEU, 2004, p. 22, grifo do autor). De tal modo, nota-se que a autonomia do campo da aquisição de linguagem refere-se não apenas a sua característica de mobilidade - está presente em diferentes campos -, mas também a sua lógica própria de atenuar as pressões externas ou, como diz Bourdieu, de refratar as demandas externas. A evolução do campo da aquisição de linguagem evidencia seu crescimento e sua autonomia. De fato, independentemente das pressões e dos fatores externos, o campo manteve sua lógica própria e apresentou um constante avanço, seja na configuração de linhas de pesquisas em programas de pós-graduação stricto sensu, seja na produção do conhecimento em constante diálogo com as subáreas da linguística e com diferentes campos do conhecimento.

Figura 2- Localização geográfica dos grupos de pesquisa.

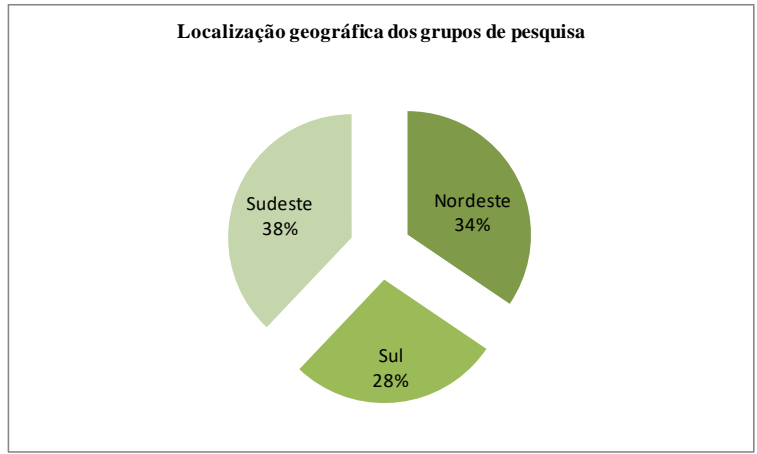

Fonte: Elaboração do autor. 
Os grupos de pesquisa sobre a aquisição de linguagem que compõem a amostra da pesquisa concentram-se em três regiões geográficas brasileiras: Sudeste, Sul e Nordeste. A Figura 2 revela que, dos 29 grupos de pesquisa, $28 \%$ localizam-se na região Sul, $38 \%$, na região Sudeste e $34 \%$, na região Nordeste do Brasil. A pesquisa sinaliza a ausência de grupos de pesquisas sobre aquisição de linguagem nas regiões Norte e Centro-Oeste do Brasil.

Deve-se, porém, observar que, embora a amostra não evidencie grupos de pesquisas nas regiões Norte e Centro-Oeste do país, é provável que pesquisadores dessas regiões estejam vinculados a grupos de pesquisa e a instituições que desenvolvem pesquisas sobre aquisição de linguagem em outras regiões. Assim, é provável que existam grupos de pesquisa que não usam os descritores na nomeação do grupo e das linhas pesquisa empregados na realização de buscas na plataforma do Diretório dos Grupos de Pesquisa do CNPq, conforme descrito na metodologia do estudo. Portanto, os dados sugerem a necessidade de outras pesquisas para identificar grupos de pesquisa nas diferentes regiões geográficas do Brasil.

Tabela 3 - IES, programas de pós-graduação e linhas de pesquisa.

\begin{tabular}{|l|l|l|}
\hline \multicolumn{1}{|c|}{ IES } & Programa & \multicolumn{1}{|c|}{$\begin{array}{c}\text { Linha de Pesquisa do Programa de Pós- } \\
\text { Graduação }\end{array}$} \\
\hline PUC-Rio & $\begin{array}{l}\text { Estudos da } \\
\text { Linguagem }\end{array}$ & $\begin{array}{l}\text { Língua e Cognição: Representação, } \\
\text { Processamento e Aquisição da Linguagem }\end{array}$ \\
\hline PUC-RS & Letras & Teorias e Uso da Linguagem \\
\hline PUC-SP & $\begin{array}{l}\text { Linguística } \\
\text { Aplicada e } \\
\text { Estudos da } \\
\text { Linguagem }\end{array}$ & Linguagem e Patologias da Linguagem \\
\hline UEM & Letras & Ensino-Aprendizagem de Línguas \\
\hline UESB & Linguística & $\begin{array}{l}\text { Aquisição e Desenvolvimento da Linguagem } \\
\text { Típica e Atípica }\end{array}$ \\
\hline UFAL & $\begin{array}{l}\text { Linguística } \\
\text { e Literatura }\end{array}$ & Teoria e Análise Linguística \\
\hline UFC & Linguística & $\begin{array}{l}\text { Aquisição, Desenvolvimento e Processamento } \\
\text { da Linguagem }\end{array}$ \\
\hline UFJF & Linguística & Linguística e Cognição \\
\hline
\end{tabular}




\begin{tabular}{|c|c|c|}
\hline UFMG & \begin{tabular}{|l|} 
Estudos \\
Linguístico \\
\end{tabular} & Estudos Formais de Língua \\
\hline \multirow[t]{2}{*}{ UFPB } & \multirow[t]{2}{*}{ Linguística } & $\begin{array}{l}\text { Aquisição de Linguagem e Processamento } \\
\text { Linguístico }\end{array}$ \\
\hline & & Linguagem, Sentido e Cognição \\
\hline UFPEL & Letras & Aquisição, Variação e Ensino \\
\hline UFRGS & Letras & Psicolinguística \\
\hline UFRJ & Linguística & Gramática na Teoria Gerativa \\
\hline \multirow[t]{2}{*}{ UFSC } & Inglês & Linguagem e Cognição \\
\hline & Linguística & Aquisição e Processamento da Linguagem \\
\hline UFSCar & Linguística & Ensino e Aprendizagem de Línguas \\
\hline UNESP & \begin{tabular}{|l|} 
Linguística \\
e Língua \\
Portuguesa \\
\end{tabular} & $\begin{array}{l}\text { Análise Fonológica, Morfossintática, Semântica } \\
\text { e Pragmática }\end{array}$ \\
\hline \multirow[t]{2}{*}{ UNICAMP } & \multirow[t]{2}{*}{ Linguística } & $\begin{array}{l}\text { Forma e Funcionamento das Línguas Naturais/ } \\
\text { Gramática/ Sintaxe Gerativa das Línguas } \\
\text { Naturais }\end{array}$ \\
\hline & & $\begin{array}{l}\text { Linguagem e Pensamento/ Psicolinguística/ } \\
\text { Neurolinguística/ Aquisição de Linguagem - } \\
\text { Cérebro, mente e linguagem/ A Fala e a Escrita } \\
\text { da Criança }\end{array}$ \\
\hline UNICAP & \begin{tabular}{|l|} 
Ciências da \\
Linguagem
\end{tabular} & $\begin{array}{l}\text { Aquisição, Desenvolvimento e Distúrbios da } \\
\text { Linguagem em suas Diversas Manifestações }\end{array}$ \\
\hline UNISC & Letras & Estudos Linguísticos e Cognição \\
\hline UNISINOS & $\begin{array}{l}\text { Linguística } \\
\text { Aplicada }\end{array}$ & Linguagem e Práticas Escolares \\
\hline USP & \begin{tabular}{|l|} 
Semiótica e \\
Linguística \\
Geral
\end{tabular} & $\begin{array}{l}\text { Estudo dos Processos de Aquisição e } \\
\text { Aprendizagem de Línguas }\end{array}$ \\
\hline
\end{tabular}

Fonte: Elaboração do autor.

Constata-se que os 29 grupos de pesquisa que compõem a amostra vinculam-se a 22 programas de pós-graduação registrados na grande área do $\mathrm{CNPq}$ Letras e Linguística: 16 estão ligados a programas de pós-graduação de universidades públicas (federais e estaduais) e 6, a universidades particulares e/ou comunitárias. Destaca-se a importância da universidade pública no desenvolvimento da pesquisa e na formação de pesquisadores no campo da Aquisição de Linguagem. Nota-se, 
portanto, que a aquisição de linguagem possui uma presença expressiva em programas de pós-graduação e, na maioria deles, configura-se como uma linha de pesquisa.

Os resultados da pesquisa revelam ainda que o campo da aquisição de linguagem mostra-se autônomo e com um terreno fértil para problematizar questões que mantêm relação com a aquisição, como é o caso das patologias, dos distúrbios e dos desvios de linguagem. Os estudos das patologias e dos distúrbios de linguagem têm expressividade na amostra que reúne os grupos de pesquisa e os programas de pós-graduação aos quais estão vinculados, ou seja, no delineamento de linhas de pesquisas em programas de pós-graduação e nos grupos de pesquisa.

Lier-DeVitto (2009) observou que as patologias da linguagem permaneciam à margem dos estudos linguísticos. Para essa pesquisadora, havia, naquela época, um número restrito de pesquisadores e de instituições de ensino e pesquisa dedicados à pesquisa sobre as patologias da linguagem no campo dos estudos da linguagem. Contudo, com base nos resultados da pesquisa, constata-se um crescimento significativo dessa temática na linguística, mais especificamente no campo da aquisição de linguagem, no que se refere tanto à abertura de grupos de pesquisa quanto à definição de linhas de pesquisa em programas de pós-graduação da área de Letras e Linguística. O crescente interesse de pesquisadores pelo estudo das patologias, dos distúrbios e dos desvios de linguagem circunscreve subáreas da Linguística - aquisição de linguagem, neurolinguística e psicolinguística.

Destaca-se que a ampliação e a discussão teórica, no campo da aquisição de linguagem, têm ocorrido a partir de indagações da Fonoaudiologia. Em outros termos, as questões advindas da clínica fonoaudiológica têm alimentado a agenda de pesquisa e proposto diversas possibilidades de teorização e/ou de interrogação da teoria e do campo. A relação entre Aquisição de Linguagem e Fonoaudiologia é objeto de discussão e de teorização (LIER-DEVITTO, 1994; LIERDEVITTO; ARANTES, 2006; YAVAS, 1990; YAVAS; HERNANDONERA; LAMPRECHT, 1991). Mais especificamente, no campo da aquisição de linguagem, a discussão teórica sobre falas e escritas desviantes na clínica fonoaudiológica possibilitou desdobramentos na proposição da clínica de linguagem, conforme 
trabalhos do grupo de pesquisa "Aquisição, Patologias e Clínica de Linguagem", coordenado por Lier-DeVitto, na PUC-SP. Em suma, clínica de linguagem refere-se à teorização da experiência clínica de fonoaudiólogas filiadas ao grupo. Entretanto, a expressão "clínica de linguagem" é um termo frequente em alguns grupos de pesquisa que compõem a amostra, na definição de linhas de pesquisas ou como descritor do grupo de pesquisa. Enfatiza-se ainda que as questões de linguagem, alfabetização e letramento, do campo da educação, ampliam a agenda de pesquisa em aquisição de linguagem.

\subsection{Sobre temas frequentes nas linhas de pesquisa}

Conforme comentado anteriormente, o campo da aquisição de linguagem tem como objeto a fala da criança ou a linguagem da criança, conforme a perspectiva teórica adotada. Entretanto, pela natureza e pela especificidade do campo, observa-se que há uma ampliação de questões de pesquisa. Nesse sentido, Scarpa (2012, p. 243-244) descreve as principais questões que norteiam o campo da aquisição de linguagem, que, por conseguinte, contribuem para pensar em uma agenda de pesquisa. São elas: a) aquisição da língua materna, no que diz respeito a aspectos convencionais e a desvios (alterações, distúrbios e atraso de linguagem) e aos componentes linguísticos (fonologia, semântica, pragmática, sintaxe, morfologia, entre outros); b) aquisição de uma segunda língua, bilinguismo em situação escolar e/ou de imersão linguística; c) aquisição da escrita, letramento, alfabetização e relação entre fala e escrita (SCARPA, 2012, p. 243-244).

A Figura 6, a seguir, com base na análise dos grupos de pesquisa que compõem a amostra, sinaliza alguns temas presentes no campo da aquisição de linguagem no Brasil. Destaca-se que é provável que outros temas figurem nas pesquisas, embora não sejam mencionados ou não apareçam com frequência.

Tabela 4 - Temas frequentes nos grupos de pesquisa.

\begin{tabular}{|l|}
\hline \multicolumn{1}{|c|}{ Temas frequentes } \\
\hline Aquisição de linguagem \\
\hline Fala e escrita \\
\hline Distúrbios de linguagem \\
\hline Desvios e patologias de linguagem \\
\hline
\end{tabular}




\begin{tabular}{|l|}
\hline Desenvolvimento da linguagem típico e atípico \\
\hline Cérebro, mente, linguagem \\
\hline Clínica de linguagem \\
\hline Aquisição de língua de sinais \\
\hline Aquisição-aprendizagem de linguagem \\
\hline Linguagem da criança e do adulto \\
\hline Aquisição e processamento de linguagem \\
\hline
\end{tabular}

Fonte: Elaboração do autor.

Conforme discutido anteriormente, com base em Bourdieu (2004), o campo de conhecimento possui uma lógica própria, ou seja, ele não se organiza ao acaso. $\mathrm{O}$ campo da aquisição de linguagem não foge à regra de outros campos de conhecimento. Ele possui uma organização própria e uma agenda de pesquisa própria que permitem o desenvolvimento de questões pertinentes. Por outro lado, o pesquisador está inserido numa dimensão política e histórica que influi na produção do conhecimento. O pesquisador está na relação de assujeitamento ao campo (BOURDIEU, 2004) ou ao dispositivo (AGAMBEN, 2009). Assim como o dispositivo, o campo de conhecimento é um "campo de forças e um campo de lutas para conservar ou transformar esse campo de forças" (BOURDIEU, 2004, p. 22-23). Esse campo ou dispositivo comporta uma relação de forças e de dominação em constante movimento.

Segundo Bourdieu (2004, p. 25), no campo do conhecimento, os pesquisadores, as instituições e as pesquisas dominantes "[...] definem o que é, num dado momento do tempo, o conjunto de objetos importantes, isto é, o conjunto das questões que importam para os pesquisadores, sobre as quais eles vão concentrar seus esforços". Em outra perspectiva, destaca-se que a relação entre o pesquisador e o campo de pesquisa é caracterizada, por um lado, por um traço de identificação que remete a aspectos da interioridade do humano e, por outro, pela própria lógica do campo de investigação.

Conforme foi assinalado por Lemos e Campos (1976), na década de 70 do século $\mathrm{XX}$, os pesquisadores tentavam aplicar o modelo piagetiano aos estudos da aquisição de linguagem sob forte influência de incongruência das "gramáticas pivô" na descrição da linguagem da criança, das dificuldades empíricas da hipótese inatista e da preocupação com a ontogênese. Esse parece ser o cenário da aquisição 
de linguagem daquela época. Atualmente, os seus pesquisadores concentram seus esforços em outras questões que demandam investimento. A Figura 6, que mostra os temas frequentes nas linhas de pesquisa dos grupos que compõem a amostra da análise, já delineia uma agenda de pesquisas com questões contemporâneas - porém não desvinculadas das questões históricas que constituem o campo.

\section{Algumas considerações}

Do trabalho desenvolvido, conclui-se que a plataforma do DGP/CNPq é importante para a identificação, a compreensão e o acompanhamento de atividades de pesquisa de pesquisadores brasileiros. A pesquisa evidenciou que, desde a sua institucionalização em meados da década de 70, o campo da aquisição de linguagem mostra crescimento crescente na linguística brasileira, caracterizando-se como um campo autônomo, híbrido, móvel e plural. Esse campo de pesquisa apresenta as seguintes características: a) conta com uma agenda de pesquisa constituída; b) está presente nas linhas de pesquisa em programas de pós-graduação stricto sensu na área de Letras e Linguística; c) está presente em grupos de pesquisa cadastrados no Diretório de Grupos de Pesquisa do $\mathrm{CNPq}$; d) é desenvolvido por pesquisadores, havendo pesquisas em andamento. A aquisição de linguagem assume, assim, um lugar de destaque na linguística brasileira não apenas como campo de pesquisa, mas também como disciplina que faz parte do currículo de vários cursos de graduação (fonoaudiologia, psicologia, letras, linguística, pedagogia, psicopedagogia, entre outros).

Pode-se dimensionar a área de estudos no Brasil e verificar desdobramentos e avanços consideráveis. Esse campo apresenta-se como um dos mais promissores dos estudos da linguagem, dada a sua lógica própria e a natureza do objeto de pesquisa que alimenta a agenda de estudos e pesquisas, ensejando o surgimento de novas teorizações. Portanto, as "limitações" e os "problemas" teóricos e metodológicos atribuídos à área não se sustentam. Segundo Lemos (1982, p. 120), no campo da aquisição de linguagem, "o dilema" - assinala a autora - é um "falso dilema que tem origem em um equívoco: o de tentar projetar teorias construídas a partir da análise de objetos - homegeneizados e abstraídos de sua relação com o sujeito - sobre a atividade linguística desse mesmo sujeito". 


\section{Referências}

AGAMBEN, G. O que é o contemporâneo? E outros ensaios. Tradução de Vinicius Nicastro Honesco. Chapecó, SC: Argos, 2009. ALBANO, E. C.; FRANÇOZO, E. Virtudes e vicissitudes do cognitivismo, revisitadas. In: MUSSALIM, F; BENTES, A. C. (org.). Introdução à linguística: fundamentos epistemológicos. São Paulo: Cortez, 2004. v. 3, p. 301-310.

ARANTES, L. M. G. Erro sintomático (ou não): a questão diagnóstica. Letras de Hoje, Porto Alegre, v. 39, n. 3, p. 337-344, set. 2004.

AUROUX, S. A revolução tecnológica da gramatização. Tradução de Eni Puccinelli Orlandi. Campinas: Unicamp, 2014.

BOURDIEU, P. Os usos sociais da ciência: por uma sociologia clínica do campo científico. São Paulo: Editora da UNESP, 2004.

BRASIL. Ministério da Educação. REUNI: Reestruturação e Expansão das Universidades Federais: diretrizes gerais. Brasília, DF: MEC, 2007. CARVALHO, G. M. M. de. A singularidade em aquisição de linguagem: um impasse metodológico. Letras de Hoje, Porto Alegre, v. 39, n. 3, p. 27-36, set. 2004.

CARVALHO, G. M. M. de. Erro de pessoa: levantamento de questões sobre o equívoco em aquisição da linguagem. 1995. 155 f. Tese (Doutorado em Linguística) - Instituto de Estudos da Linguagem, Universidade Estadual de Campinas, Campinas, 1995.

CASTRO, M. F. C. P. de. Piaget, o método clínico e a linguagem. In: CASTRO, M. F. C. P. de (org.). O método e o dado no estudo da linguagem. Campinas: Editora da Unicamp, 1996. p. 165-178.

CASTRO, M. F. C. P. de. Processos dialógicos e construção de inferências e justificativas na aquisição da linguagem. 1985. $307 \mathrm{f}$. Tese (Doutorado em Linguística) - Instituto de Estudos da Linguagem, Universidade Estadual de Campinas, Campinas, 1985.

CASTRO, M. F. C. P. de. Questões sobre a infância e a fala da criança na teorização sobre a aquisição da linguagem. Revista da ABRALIN, [s.l.], n. especial, p. 63-76, 2011.

CASTRO, M. F. C. P. de; FIGUEIRA, R. A. Aquisição da linguagem. In: PFEIFFER, C. C; NUNES, J. H. (org.). Introdução às ciências da linguagem: linguagem, história e conhecimento. Campinas: Pontes, 2006. p. 73-102.

CHOMSKY, N. O programa minimalista. Tradução de Eduardo Paiva Raposo. Alfragide, Portugal: Editorial Caminho, 2007. 
CHOMSKY, N. Reflexões sobre a linguagem. Tradução de Carlos Vogt, Cláudia Tereza Guimarães de Lemos, Maria Bernadete Abaurre Cnerre, Clarice Sabóia Madureira e Vera Lúcia Maia de Oliveira. São Paulo: Cultrix, 1980.

CORRÊA, L. M. S. Conciliando processamento linguístico e teoria de língua no estudo da aquisição da linguagem. In: CORRÊA, L. M. S. (org.). Aquisição da linguagem e problemas do desenvolvimento linguístico. Rio de Janeiro: Editora PUC-Rio; São Paulo: Loyola, 2006. p. 29-86.

ELLIOT, A. J. A linguagem da criança. Rio de Janeiro: Zahar, 1982. FIGUEIRA, R. A. A criança na língua: marcas de subjetivação na aquisição do gênero. Letras de Hoje, Porto Alegre, v. 39, n. 3, p. 6174, set. 2004.

FIGUEIRA, R. A. Causatividade: um estudo longitudinal de suas principais manifestações no processo de aquisição do português por uma criança. 1985. 348 f. Tese (Doutorado em Linguística) - Instituto de Estudos da Linguagem, Universidade Estadual de Campinas, Campinas, 1985.

FIGUEIRA, R. A. Em torno da analogia: a contribuição de Saussure para a análise da fala da criança. Revista Prolingua, João Pessoa, v. 10, n. 1, p. 174-189, jan./fev. 2015.

FIGUEIRA, R. A. Inovações na expressão de agentividade: episódios marcantes da trajetória linguística da criança. Revista Linguística, Montevideo, v. 35, n. 2, p. 105-127, 2019.

FIGUEIRA, R. A. O erro como dado de eleição nos estudos de aquisição da linguagem. In: CASTRO, M. F. C. P. de (org.). O método e o dado no estudo da linguagem. Campinas: Editora da Unicamp, 1996. p. 55-86.

FLETCHER, P.; MACWHINNEY, B. Compêndio da linguagem da criança. Porto Alegre: Artes Médicas, 1995.

JAKOBSON, R. A linguística em suas relações com as outras ciências. In: JAKOBSON, R. Línguística, poética e cinema. 3. reimpr. São Paulo: Perspectiva, 2015. p. 11-64.

KATO, M. A. Aquisição da linguagem numa abordagem gerativista. Letras de Hoje, Porto Alegre, v. 34, n. 3, p. 17-25, set. 1999. 
LEMOS, C. T. G. de. A criança e o linguista: modos de habitar a língua? Estudos Linguísticos, São Paulo, v. 43, n. 2, p. 954-964, maio/ago. 2014.

LEMOS, C. T. G. de. Das vicissitudes da fala da criança e de sua investigação. Caderno de Estudos Linguísticos, Campinas, n. 42, p. 41-69, jan./jun. 2002.

LEMOS, C. T. G. de. Desenvolvimento da linguagem e processo de subjetivação. ComCiência, SBPC, 10 ago. 2001. Disponível em: http://www.comciencia.br/dossies-1-

72/reportagens/linguagem/ling 17.htm\#notas. Acesso em: 10 jan. 2020. LEMOS, C. T. G. de. Los procesos metafóricos y metonímicos como mecanismos de cambio. Substratum, Barcelona, v. 1, n. 1, p. 121-135, 1992.

LEMOS, C. T. G. de. Sobre aquisição de linguagem e seu dilema (pecado) original. Boletim da Abralin, Recife, n. 3, p. 97-126, 1982.

LEMOS, C. T. G. de. Sobre os pronomes pessoais na fala da criança. Letras de Hoje, Porto Alegre, v. 39, n. 3, p. 9-25, set. 2004.

LEMOS, C. T. G. de. Uma crítica (radical) à noção de desenvolvimento na aquisição da linguagem. In: LIER-DEVITTO, M. F; ARANTES, L. (org.). Aquisição, patologias e clínica de linguagem. São Paulo: Editora PUC-SP, 2006. p. 21-32.

LEMOS, C. T. G. de; CAMPOS, M. F. P. de Castro. Algumas observações sobre a utilização do modelo piagetiano em recentes estudos de aquisição da linguagem. Caderno de Estudos Linguísticos, Campinas, v. 1, n. 1, p. 51-63, 1976.

LEMOS, M. T. G. A fala da criança como interpretação. Cadernos de Estudos Linguísticos, Campinas, v. 29, p. 17-26, 1995.

LIER-DEVITTO, M. F. Constituição do interlocutor vocal. 1983. Dissertação (Mestrado em Linguística Aplicada e Estudo da Linguagem) - Pontifícia Universidade Católica de São Paulo, 1983.

LIER-DEVITTO, M. F. Fonoaudiologia: no sentido da linguagem. São Paulo: Cortez, 1994.

LIER-DEVITTO, M. F. On pathological speech: the history of a symptomatic repetition. The ESPecialist, São Paulo, v. 30, n. 1, p. 117, 2009.

LIER-DEVITTO, M. F. Os monólogos da criança: delírios da língua. São Paulo: EDUC/Fapesp, 1998. 
LIER-DEVITTO, M. F. Patologias da linguagem: sobre as "vicissitudes de falas sintomáticas". In: LIER-DEVITTO, M. F; ARANTES, L. (org.). Aquisição, patologias e clínica de linguagem. São Paulo: Editora PUC-SP, 2006. p. 79-96.

LIER-DEVITTO, M. F. Sobre o sintoma: déficit de linguagem, efeito da fala no outro, ou ainda...? Letras de Hoje, Porto Alegre, v. 36, n. 3, p. 245-251, set. 2001.

LIER-DEVITTO, M. F.; ARANTES, L. (org.). Aquisição, patologias e clínica de linguagem. São Paulo: Editora PUC-SP, 2006.

MAIA, E. A. da M. A dialética da gênese e do empréstimo na constituição da psicolinguística. Delta: Documentação e Estudos em Linguística Teórica e Aplicada, São Paulo, v. 1, n. 1 e 2, p. 95-106, 1985.

MORIN, E. A cabeça bem-feita: repensar a reforma, reformar o pensamento. Rio de Janeiro: Bertrand Brasil, 2012.

PERRONI, M. C. O que é o dado em aquisição da linguagem. In: CASTRO, M. F. C. P. de (org.). O método e o dado no estudo da linguagem. Campinas: Editora da Unicamp, 1996. p. 15-29.

ROBINS, R. H. Linguística geral. Rio de Janeiro: Globo, 1981.

SCARPA, E. M. Aquisição da linguagem. In: MUSSALIM, F.; BENTES, A. C. (org.). Introdução à linguística: domínios e fronteiras. São Paulo: Cortez, 2012. v. 2. p. 203-232.

YAVAS, M. S. Desvios fonológicos em crianças - teoria, pesquisa e tratamento. Porto Alegre: Mercado Aberto, 1990.

YAVAS, M. S; HERNANDORENA, C. L. M; LAMPRECHT, R. R. Avaliação fonológica da criança: reeducação e terapia. Porto Alegre: Artes Médicas, 1991.

\section{Notas}

* Fonoaudiólogo. Doutor em Linguística Aplicada e Estudos da Linguagem pela Pontifícia Universidade Católica de São Paulo (PUC-SP). Professor Adjunto da Universidade Federal do Pará (UFPA).

${ }^{1}$ Reconhece-se que os termos "aquisição de linguagem" e "aquisição da linguagem" podem indicar uma diferença teórica, bem como os termos "fala da criança" (child language) e "aquisição de/da linguagem" (language acquisition). Entretanto, essa questão não será aqui problematizada por fugir do escopo do trabalho. Empregar-se-á 
a expressão "aquisição de linguagem" para referir-se ao campo de estudo constituído por uma pluralidade teórica.

${ }^{2}$ Cf. Castro (1996), um estudo sobre os impasses do método clínico na teoria piagetiana e a natureza da linguagem.

${ }^{3}$ Uma explanação sobre o cognitivismo enquanto programa de pesquisa que influenciou sobremaneira a Linguística encontra-se em Albano e Françozo (2004).

4 Neste trabalho, não se faz apelo a nenhuma das definições existentes de interdisciplinaridade. Adotam-se, então, os termos "híbrido" e "hibridação" para referir-se ao encontro ou à inter-relação entre diferentes campos do conhecimento na configuração de programas de pesquisa em aquisição de linguagem.

${ }^{5}$ Destaca-se que na Linguística não há apenas uma perspectiva teórica no campo da aquisição de linguagem. Pelo menos duas vertentes linguísticas são possíveis: estudos sobre a fala da criança, conforme Lemos (1982, 1992, 2002, 2006) e colaboradoras (CARVALHO, 1995, 2004; CASTRO, 1985, 2011; FIGUEIRA, 1985, 2019; LIERDEVITTO, 1983, 1998), e estudos da aquisição da linguagem, a partir da perspectiva gerativa. Essa última perspectiva não é por si uma teoria da aquisição de linguagem. Por assumir os pressupostos da tese inatista, da gramática universal (GU), como "sistema de princípios, condições e regras" universal (CHOMSKY, 1980, p. 28), e por postular que a faculdade da linguagem possui um estado inicial geneticamente determinado e um estado final, a concepção biológica da linguagem, ou melhor, a concepção da linguagem como órgão mental particular - faculdade da linguagem esbarra em questões atinentes ao problema da aquisição de linguagem, o que favorece o desenvolvimento de pesquisas nesse prisma teórico. Destaca-se ainda que Chomsky (2007) reconhece a importância do problema da aquisição de linguagem no estudo da linguagem, visto que considera como "problemas clássicos do estudo da linguagem" as seguintes questões: a) o que a criança "sabe quando possui uma língua particular", b) como a criança "adquiriu esse conhecimento", c) como a criança "põe esse conhecimento em uso", d) "como é que estas propriedades da mente/cérebro evoluíram na espécie" e e) "como é que estas propriedades se realizam nos mecanismos do cérebro" (CHOMSKY, 2007, p. 55). Em outros termos, o problema da aquisição de linguagem é inerente aos estudos linguísticos, conforme mencionado anteriormente. Cumpre destacar que não é objetivo deste trabalho deter-se em aspectos do problema da aquisição de linguagem no programa gerativista, nem realizar um contraponto à proposta de Lemos.

6 prosta de Lemos.

$\mathrm{CNPq} / \mathrm{DGP}$.

Disponível

em:

http://dgp.cnpq.br/dgp/faces/consulta/consulta_parametrizada.jsf. Acesso em: 30 maio 2020.

${ }^{7}$ Cf. CNPq. Disponível em: http://lattes.cnpq.br/. Acesso em: 22 ago. 2020. 